\title{
Microbial food resources of the macrofaunal- deposit feeder Ptychodera bahamensis (Hemichordata: Enteropneusta)
}

\author{
Fred C. Dobbs ${ }^{1, *}$, James B. Guckert ${ }^{2}$ \\ ${ }^{1}$ Department of Oceanography, Florida State University, Tallahassee, Florida 32306, USA \\ ${ }^{2}$ Department of Microbiology, Montana State University, Bozeman, Montana 59717, USA
}

\begin{abstract}
Biochemical and traditional analyses were used to characterize the microbial food resources and digestive efficiency of Ptychodera bahamensis, an enteropneust hemichordate. Sediment was collected from freshly extruded fecal casts and adjacent feeding depressions. There were no significant differences between casts and depressions in median grain size, percent silt-clay, density of total meiofauna and of nematodes, and concentrations of chlorophyll a and phaeophytin. Nematodes in. casts had a median diameter greater than those in depressions. Measures of total, viable microbial biomass were $30 \%$ (total phospholipid, ester-linked fatty acids) and $49 \%$ (extractible phospholipid phosphate) lower in casts. Concentrations of 33 fatty acids were lower in casts, indicating that the hemichordate digests a wide variety of microorganisms. Only 18:1 $17 \mathrm{c}$ (cis-vaccenic acid) was not lower in casts than in depressions. This fatty acid is characteristic of eubacteria having the anaerobicdesaturase pathway, many of which are Gram-negative organisms. P. bahamensis either cannot digest this functional group of bacteria or contributes gut microbes containing $18: 1 \omega 7 \mathrm{c}$ to sediment passing through its alimentary canal.
\end{abstract}

\section{INTRODUCTION}

Benthic ecologists have long been interested in the microbial food resources of animals that ingest sediment, yet it usually is difficult to define exactly what those resources are. Many investigations have been limited to non-specific analyses, e. g. ATP and organic carbon, from which it is impossible to ascertain digestion of specific microbial populations. Direct counts can distinguish between bacteria and diatoms, but are of little benefit in assessing other microbial groups.

As an alternative, quantitative extraction of cellular components having rapid turnover permits an assessment of the viable microbial community's biomass and composition without the problems associated with direct enumeration or cultural methods (White 1986). In particular, phospholipid, ester-linked fatty acids have proven to be reproducible, capable indicators of a wide suite of microbes encountered in the environment (e. g.

\footnotetext{
- Present address: Marine Sciences Research Center, SUNY
} Stony Brook, Stony Brook, New York 11794-5000, USA
Guckert et al. 1985). An organism's fatty acid profile is a phenotypic description of its biochemical capabilities and provides investigators with a powerful, discriminating tool.

We have studied the deposit feeding of Pytchodera bahamensis, an enteropneust hemichordate abundant inter- and subtidally along the Gulf Coast of the Florida Panhandle, USA. P. bahamensis inhabits deep burrows and its modes of feeding and defecation are analogous to those of arenicolid polychaetes and leptosynaptid holothurians, i. e. it is a 'funnel feeder'. Previous investigations of feeding by other enteropneusts include those of Cori (1902). Stiasny (1910), Barrington (1940), and Knight-Jones (1953). However, none of these previous studies has been microbiological in character. In fact, most of what is known concerning microbiological aspects of bulk feeding by deposit feeders, i. e. ingestion of tens to hundreds of grams of sediment per day, stems from studies of surface-dwelling holothurians (e. g. Yingst 1976, Moriarty 1982, Hammond 1983, Baird \& Thistle 1986). For only one group of subsurface-bulk ingestors, the arenicolid polychaetes, is any 
information available on microbes' potential as nourishment. Hylleberg (1975) observed that ciliates, flagellates, small nematodes, and some bacteria were digested by Abarenicola pacifica. Boon et al. (1978) showed that Arenicola marina contained algal- and bacterial-derived fatty acids, implying that microbes are a food resource. Rijken (1979) demonstrated that addition of bacteria or diatoms to sediments increased growth of juvenile $A$. marina in short-term (2 wk) experiments. It was not clear, however, whether the worms utilized living microorganisms or non-living organic matter.

The specific intent of the present study was to deduce the microbial food resources and the digestive capabilities of Ptychodera bahamensis. While traditional analyses were included in the research (e.g. granulometry and meiofaunal counts), emphasis was placed on the use of phospholipid fatty acids to characterize the worm's resources at the level of functional groups of microbes.

\section{MATERIALS AND METHODS}

Organism. Ptychodera bahamensis (hereafter Ptychodera) lives in a burrow and feeds on surface sediments. Feeding activity causes surface sediment to slump and form a rounded depression, up to $5 \mathrm{~cm}$ deep, at one end of its burrow (Fig. 1). At the other end of its burrow, it deposits its fecal casts, structures that may rise 5 to $6 \mathrm{~cm}$ above the sediment surface. The fecal casts are 3 to $4 \mathrm{~mm}$ thick, loosely coiled, and weakly held together by a very thin mucus covering. The feeding depression and the fecal cast are the initial and final components of the deposit-feeding system of Ptychodera. The worm itself is not amenable to sam-

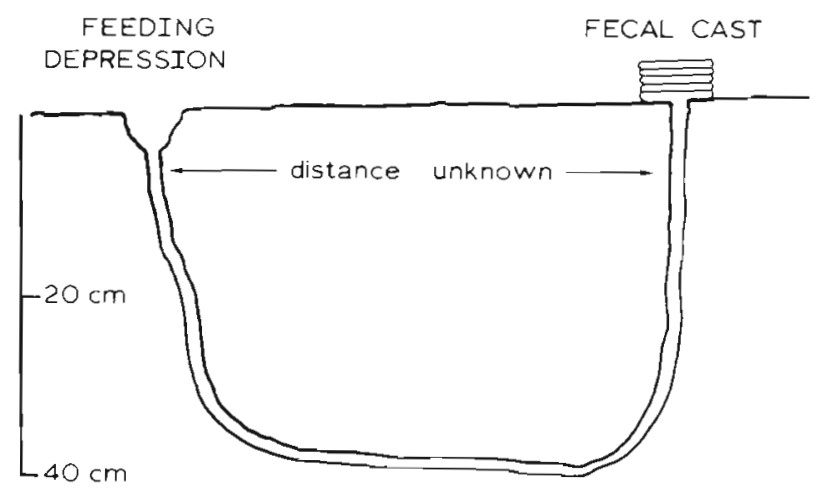

Fig. 1. Ptychodera bahamensis. Diagrammatic representation of the burrow and deposit-feeding system (after Stiasny 1910). It was not possible to associate a feeding depression with a particular fecal cast, so the distance between the two is indicated as unknown. See Duncan (1987) for a review of burrow types made by enteropneusts pling because of its highly elusive nature and, when collected, its proclivity to fragment.

In the course of subsequent work on Ptychodera, we observed substantial variability in the appearance of casts. Color, composition, and granulometry may differ within and among casts. Two end members in a spectrum of fecal casts may be defined. 'Light' casts are beige, contain very few particles less than $63 \mu \mathrm{m}$ in diameter, and have essentially no debris from vascular plant detritus. Light casts, therefore, have an appearance very similar to ambient surface sediments. 'Dark' casts are almost black, contain many particles less than $63 \mu \mathrm{m}$ in diameter (up to $10 \%$ by weight; F.C.D. unpubl.) and are composed of varying amounts of detritus from vascular plants. Light casts have total sulfide concentrations at barely detectable levels 10.02 $\mu \mathrm{mol} \mathrm{g}{ }^{-1}$ ), while dark casts have higher concentrations (0.13 $\mu \mathrm{mol} \mathrm{g}^{-1}$ ) (Kevin Carman, FSU Dept of Oceanography, pers. comm.)

Unfortunately, this variability had not been discerned when samples for this study were collected. Most fecal casts, however, are neither completely light nor completely dark. A continuum of shades typically is encountered, with only a few percent classified as end members. From a probabilistic basis, then, it was unlikely that this study's samples included end members. In fact, inspection of archived sediment indicated that none of the sampled casts were light-or dark-end members. We conclude that although we sampled a range of cast types and introduced an unanticipated source of variation, the data were not skewed, but represented central tendencies.

Field methods. The study site is an intertidal sand flat in St. George Sound, approximately $50 \mathrm{~m}$ offshore from the Florida State University Marine Laboratory, Florida, USA $\left(29^{\circ} 55.00^{\prime \prime} \mathrm{N}, 84^{\circ} 30.36^{\prime \prime} \mathrm{W}\right)$. On $28 \mathrm{Janu}-$ ary 1986, 5 fecal casts of intertidal Ptychodera were selected for sampling. Criteria for selection included an observed issuance of a cast. After sampling each cast, a corresponding set of samples was taken from the closest feeding depression. Sediment was collected using an ethanol-cleaned spatula. Samples for chlorophyll a, phaeopigments, and lipids were transferred to containers that were plunged into liquid nitrogen for several minutes and transported on dry ice to the laboratory. There, samples for lipids were lyophilized immediately; those for photopigments were stored at $-70^{\circ} \mathrm{C}$. Samples for granulometry were taken to the laboratory and frozen. Samples for meiofauna were fixed in the field with $10 \%$ buffered formalin (final concentration ca $5 \%$ ) to which Rose Bengal stain had been added

Laboratory methods. Granulometry: Particle-size distributions were estimated by wet-sieving the samples through nested sieves $(1000,500,250,125$, and 63 
$\mu \mathrm{m}$ ) using paper-filtered (Whatman \# 2) seawater. The fraction $<63 \mu \mathrm{m}$ was collected by vacuum filtration on previously dried and weighed filters (Gelman, $0.4 \mu \mathrm{m}$ ). All fractions were rinsed with distilled water to remove salts, washed into tared trays (except for the fraction $<63 \mu \mathrm{m})$, and dried to constant weight at $105^{\circ} \mathrm{C}$. Grain sizes were expressed in phi units, where the phi value is the negative $\log _{2}$ of the particle diameter in $\mathrm{mm}$.

Meiofauna: After 48 h of fixation, the samples were washed on a $63 \mu \mathrm{m}$ sieve, than transferred to $80 \%$ ethanol. Samples were later examined using a dissecting microscope and meiofauna were picked out. Densities were expressed as number of organisms $\mathrm{cm}^{-3}$. In sorting the nematodes, it was noted that specimens from casts seemed larger than those from depressions. To examine this possibility, nematodes' body diameters were determined. Using videomicroscopy, measurements were made at the level of the pharyngeal bulb, when discernible. Otherwise, diameter was measured at the worm's widest point.

Photopigments and filamentous cyanobacteria. Pigments were extracted and quantified following the procedure of Hylleberg \& Galluci (1975), a modification of the method of Lorenzen (1970). Filamentous cyanobacteria were picked from sediments sampled for meiofauna. Densities were expressed as number of filaments $\mathrm{cm}^{-3}$.

Lipids. All glassware was immersed for at least $12 \mathrm{~h}$ in $6 \mathrm{M} \mathrm{HCl}$, rinsed with deionized water, dried, and rinsed with chloroform-methanol $(1: 1, v / v)$. Lipids were extracted using a protocol modified by White et al. (1979a) from that of Bligh \& Dyer (1959). Following recovery in chloroform, replicate $3 \mathrm{ml}$ samples were withdrawn from each sample for determination of extractible phospholipid phosphate (White et al. $1979 \mathrm{~b})$. The remainder of the chloroform-extracted lipid was fractionated on a silicic-acid chromatography column (Gehron \& White 1983) into 3 general lipid classes: neutral lipids, glycolipids, and polar lipids. The fatty acids esterified to the phospholipids were methylated by mild alkaline transesterification of the polar lipid fraction (Guckert et al. 1985). The resulting fatty acid methyl esters (FAME) were separated and quantified by capillary gas chromatography using a Varian 3700 gas chromatograph with flame-ionization detection. The separation system detailed in Guckert et al. (1985) was used, except that the gas chromatograph was outfitted with dual capillary columns (HewlettPackard non-polar cross methyl silicone and Supelco polar SP-2340, both $50 \mathrm{~m} \times 0.2 \mathrm{~mm}$ ) set up in a parallel configuration from a common injector (Sonchik \& Walker 1985). FAME were quantified based on peak areas determined on the non-polar column relative to the area for an internal injection standard (C19:0). An equimolar response was assumed for all FAME in the range quantified, i. e. C14-C20. A Nelson Analytical 2600 programmable laboratory data system was used. Where co-elution of FAME peaks occurred, quantification was supplemented with the information provided by the polar column. Fatty acids were normalized to pmol $g^{-1}$ (dry weight) of sediment and fatty acid profiles were expressed as percentages of the total molar recovery.

The separated FAME were tentatively based on coelution or identical relative retention time of the sample FAME with standards obtained from Supelco, Inc., Applied Science Laboratories, Inc., and Nu-Chek Prep. Tentative identifications were also based on previously identified laboratory standards, including similar samples taken from the study site (Guckert et al. 1985). Further verification required gas chromatography/mass spectrometry (GC/MS) using a VG MM-16 mass spectrometer having a direct capillary inlet. Separate analyses were done on J \& W non-polar DB-5 and polar DB-225 capillary columns $(30 \mathrm{~m} \times 0.2 \mathrm{~mm}$ ) with this system. The identification of FAME was verified by the occurrence of characteristic fragmentation patterns reported previously (Ryhage \& Stenhagen 1958, DinhNguyen et al. 1961). The diagnostic mass-spectral fragment of saturated FAME is $\mathrm{m} / \mathrm{e}=74$, a result of a gamma-hydrogen migration to a double bond followed by a beta cleavage, a mass-spectral process commonly known as the McLafferty rearrangement (McCloskey 1970). The degree of unsaturation of FAME was also confirmed by mass-spectral interpretation (McCloskey 1970), while the position and geometry of the double bonds was inferred by the retention times on the 4 different GC-columns stationary phases used.

Fatty acids are designated as total number of carbon atoms:number of double bonds with the position of the double bond closest to the aliphatic $(\omega)$ end of the molecule indicated with the geometry ' $c$ ' for cis and ' $\mathrm{t}$ ' for trans. The prefixes ' $i$ ' and ' $a$ ' refer to iso- and anteiso-branching, respectively. Other branching is indicated as position of the additional methyl group from the carboxyl ( $\circ$ ) end, e. g. 10Me16:0. Cyclopropyl fatty acids are designated as 'cy'. All polyunsaturated fatty acids are presumed to be methylene interrupted (e. g. $18: 3 \omega 3=18: 3 \omega 3,6,9$ ).

Statistical methods. Although samples were collected in a randomized-block design, results were analysed using a non-parametric procedure for a completely randomized design, i. e. Wilcoxon's rank-sum test (Hollander \& Wolfe 1973). Statistical discrimination lost by disregarding blocks was more than compensated for by the increased power of the rank-sum test. Hurlbert (1984) considered that such a 'hybrid approach' should not raise the probability of Type I error. Unless otherwise noted, a critical value of $p=0.05$ was used 


\section{RESULTS}

\section{Granulometry}

At the study site, the ambient sediment, represented by samples from feeding depressions, is a moderately well-sorted medium-fine sand, with a silt-clay content $<0.7 \%$ by weight (Table 1 ). The corresponding samples from fecal casts were not different in either respect. Thus, differences that occur in other parameters were assumed to be independent of granulometry.

\section{Meiofauna}

A total of 856 organisms was recovered. The abundance of total meiofauna was not significantly different in casts and depressions (Table 1). Similarly, nematodes, which comprised $57 \%$ of the total meiofauna, were found in approximately equal densities in casts and depressions (Table 1). There was no difference in the ratio of nematodes to total meiofauna in casts and depressions. No differences in density were detected in other taxa, which included platyhelminths, harpacticoid copepods, tardigrades, and annelids (data not shown).

Measurements of nematodes body diameters confirmed what had been sensed while sorting; the median diameter of organisms collected from casts was greater than in those from depressions $(p<0.001)$ (Fig. 2).

\section{Photopigments and filamentous cyanobacteria}

Values of chlorophyll $a$ were almost identical in casts and depressions (Table 1), about $2.6 \mu \mathrm{g} \mathrm{g}^{-1}$ sediment (dry weight). Likewise, concentrations of phaeopigments were similar in casts and depressions, 1.35 and $1.19 \mu \mathrm{g} \mathrm{g}^{-1}$, respectively. There was no statistically significant difference between casts and depressions in chlorophyll $a$ or phaeophytin, or in their ratio to one another. On the other hand, filamentous cyanobacteria, apparently of one morphotype, exhibited significantly lower numbers in casts than in depressions (Table 1).

\section{Lipids}

Two estimates of total, viable microbial biomass were determined. Extractible phospholipid phosphate was $49 \%$ lower, and total phospholipid, ester-linked fatty acids (PLFA) were $30 \%$ lower in casts than in depressions (Table 1). To partition differences in biomass into components of the microbial community, individual PLFA were analysed.
Table 1. Characteristics of fecal casts $(n=5)$ and feeding depressions $(n=5)$ of Ptychodera bahamensis. Values represent means (standard deviation). 'PLFA': phospholipid fatty acid. Difference between casts and depressions was significant $(p<0.05)$

\begin{tabular}{|c|c|c|}
\hline Characteristic & Depressions & Casts \\
\hline Median phi & $2.24(0.05)$ & $2.19(0.06)$ \\
\hline$\%$ silt-clay & $0.66(0.34)$ & $0.52(0.40)$ \\
\hline $\begin{array}{l}\text { Meiofauna } \\
\text { (organisms } \mathrm{cm}^{-3} \text { ) }\end{array}$ & $73.8 \quad(42.9)$ & $59.0 \quad(37.0)$ \\
\hline $\begin{array}{l}\text { Nematodes } \\
\quad \text { (organisms } \mathrm{cm}^{-3} \text { ) }\end{array}$ & $32.3 \quad(9.7)$ & $43.8 \quad(22.7)$ \\
\hline Chlorophyll a $\left(\mu \mathrm{g} \mathrm{g}^{-1}\right)$ & $2.59(0.70)$ & $2.58(0.47)$ \\
\hline Phaeopigments ( $\mathrm{g} \mathrm{g}^{-1}$ ) & $1.19(0.41)$ & $1.35(0.53)$ \\
\hline $\begin{array}{l}\text { Cyanobacteria } \\
\quad\left(\text { filaments } \mathrm{cm}^{-3}\right)\end{array}$ & $43.4 \quad(36.8)$ & $8.4 \quad(15.8)^{\circ}$ \\
\hline $\begin{array}{l}\text { Phospholipid phosphate } \\
\left.\text { (nmol g }{ }^{-1}\right)\end{array}$ & $27.0 \quad(17.3)$ & $15.4 \quad(3.6)^{*}$ \\
\hline Total PLFA $\left(\mathrm{nmol} \mathrm{g}^{-1}\right)$ & $14.86(2.16)$ & $10.37(3.76)^{\circ}$ \\
\hline
\end{tabular}

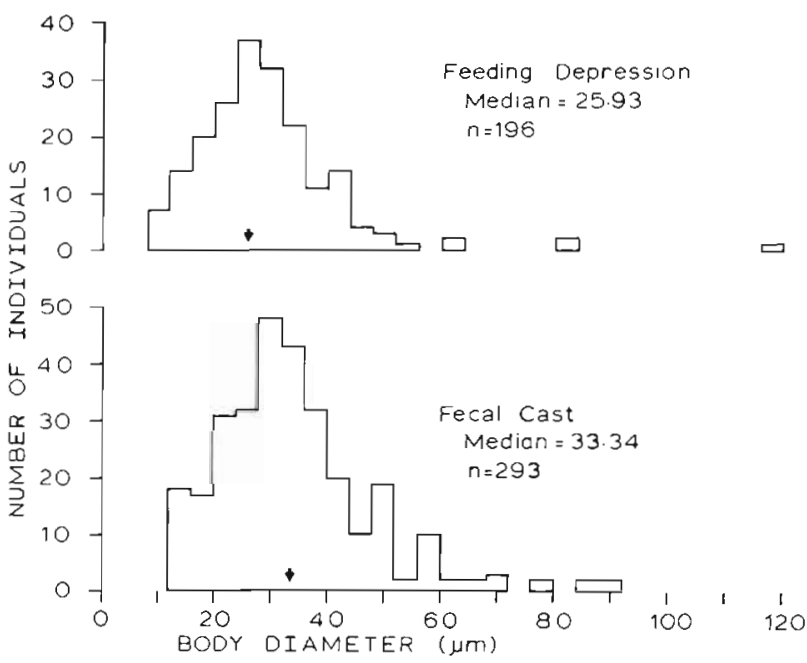

Fig. 2. Size-frequency distributions of nematodes' body diameters in samples from feeding depressions $(n=5)$ and fecal casts $(n=5)$ of Ptychodera bahamensis. Arrow indicates the median value of each distribution

Thirty-four PLFA were identified and quantified. Of these, $16: 1 \omega 7 c, 16: 0$, and $18: 1 \omega 7 \mathrm{c}$ together contributed approximately $50 \%$ of the fatty acid biomass; 10 other fatty acids were among those each comprising $2 \%$ or more (Table 2). These 13 fatty acids comprised more than $80 \%$ of all fatty acid biomass. All fatty acids and their concentrations are listed in the Appendix. Only two of the dominant fatty acids showed a significant difference in their relative contributions to microbial communities in casts and depressions. The straightchain 15:0 exhibited a slightly lower value in casts 
$(4.27 \%)$ than in depressions $(5.94 \%)$. The monoenoic 18: $1 \omega 7 \mathrm{C}$ contributed $8.51 \%$ in depressions and $12.34 \%$ in casts.

Every identified PLFA, except 18:10 7c, was more abundant in depressions than in casts (Appendix). Among the dominant fatty acids, all save $18: 1 \omega 7 \mathrm{C}$ had

Table 2. Dominant fatty acids $(>2 \%$ of total phospholipid fatty acids in either location) in the feeding depressions $(n=5)$ and fecal casts $(n=5)$ of Ptychodera bahamensis. Values represent the mean (standard deviation) percent contributed by the fatty acid to total fatty acid biomass. - Difference between casts and depressions was significant $(p \leq 0.05)$

\begin{tabular}{|lrr|}
\hline Fatty acid & Depressions & \multicolumn{1}{c|}{ Casts } \\
\hline $14: 0$ & $3.24(0.52)$ & $2.61(0.98)$ \\
$115: 0$ & $3.00(0.36)$ & $2.16(1.07)$ \\
a $15: 0$ & $5.07(0.61)$ & $4.49(1.82)$ \\
$15: 0$ & $5.94(0.77)$ & $4.27(1.02)$ \\
$16: 1 \omega 7 \mathrm{c}$ & $17.74(1.69)$ & $18.16(4.22)$ \\
$16: 0$ & $21.04(3.88)$ & $21.84(1.91)$ \\
$10 \mathrm{Me} 16: 0$ & $1.95(0.20)$ & $2.19(1.21)$ \\
$17: 1 \omega 8 \mathrm{c}$ & $4.40(0.87)$ & $4.01(0.79)$ \\
$18: 1 \omega 9 \mathrm{C}$ & $2.67(0.19)$ & $2.74(0.66)$ \\
$18: 1 \omega 7 \mathrm{C}$ & $8.51(0.95)$ & $12.34(1.63)$ \\
$18: 0$ & $2.82(0.38)$ & $2.42(0.57)$ \\
$20: 4 \omega 6$ & $2.76(0.67)$ & $2.50(0.93)$ \\
$20: 5 \omega 3$ & $4.02(0.67)$ & $4.34(0.52)$ \\
\end{tabular}

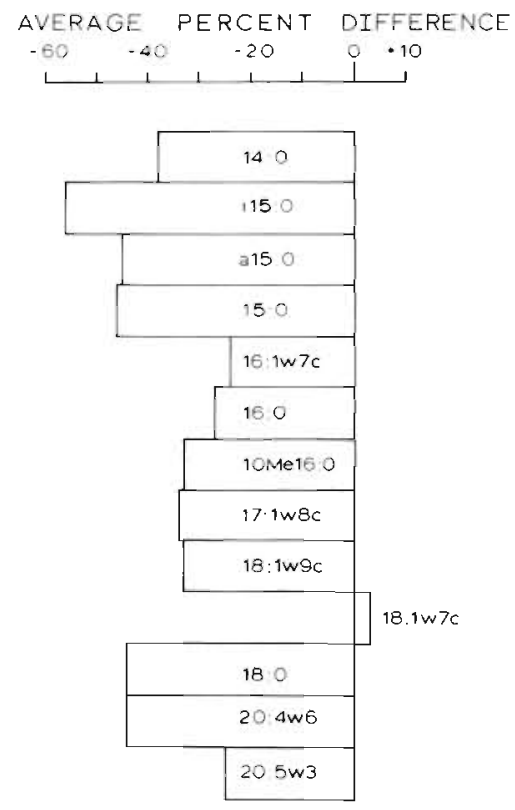

Fig. 3. Average percent difference in concentration of dominant fatty acids in feeding depressions and casts of Ptychodera bahamensis. Each bar represents the difference between the means of depression and cast values. Negative values indicate a lower concentration in casts, positive values a higher concentration in casts an average concentration in casts 24 to $56 \%$ lower than in depressions (Fig. 3). In fact, 18:167c was the only fatty acid in which the average concentration was greater in casts than in depressions, although the difference was negligible

Phospholipid fatty acids may be combined (by summing their concentrations) to define functional groups of microorganisms. For example, 18-, 20-, and 22-carbon polyunsaturated fatty acids are restricted to eukaryotes (Shaw 1966), with some possible exceptions (e. g. cyanobacteria: Kenyon 1972, Potts et al. 1987; deep-sea eubacteria: DeLong \& Yayanos 1986). Therefore, long-chain polyunsaturated fatty acids represent a measure of the eukaryotic contribution to the entire microbial community. This and other biomarker assignments are detailed in Table 3. Note that $18: 1 \omega 7 \mathrm{C}$ was used as a biomarker for bacteria having the anaerobic-desaturase pathway (Fulco 1983), one of 2 major pathways of unsaturated fatty acid synthesis in bacteria.

In a manner similar to analyses of individual fatty acids, the relative contributions of functional groups of microbes were compared (Table 4). The group of fatty acids characteristic of prokaryotes, odd chains, branched chains, and cyclopropyl derivatives, contributed about $30 \%$ to total fatty acid biomass. Polyunsaturated fatty acids, indicative of eukaryotes, accounted for about $8.5 \%$. Eukaryotic markers may be divided into the $\omega 6$ and $\omega 3$ series, sometimes referred to as the 'animal' and 'plant' series, respectively (Erwin 1973). Each subgroup of eukaryotic markers contributed about $4 \%$ to total phospholipid biomass. Fatty acid biomarkers of eukaryotic photoautotrophs also

Table 3. Assignment of phospholipid, ester-linked fatty acids to functional groups of microbes

\begin{tabular}{|c|c|}
\hline Functional group & Fatty acid(s) \\
\hline Eukaryotes & $\begin{array}{l}18: 3 \omega 6,18: 2 \omega 6,18: 3 \omega 3 \\
20: 4 \omega 6,20: 5 \omega 3^{\mathrm{a}}\end{array}$ \\
\hline$\omega 6$ 'animal' series & $18: 3 \omega 6,18: 2 \omega 6,20: 4 \omega 6^{b}$ \\
\hline$\omega 3$ 'plant' series & $18: 3 \omega 3,20: 5 w 3^{b}$ \\
\hline Eukaryotic photoautotrophs & $16: 1 \omega 13 \mathrm{t}, 18: 3 \omega 3,18: 1 \omega 9^{\mathrm{a}, \mathrm{c}}$ \\
\hline Prokaryotes & $\begin{array}{l}115: 0, \text { a } 15: 0,15: 0, i 17: 0, \text { a } 17: 0 \\
17: 0,18: 1 \omega 7 c, \text { cy } 19: 0(\omega 7,8) \\
10 \mathrm{Me} 16: 0, \text { cy } 17: 0(\omega 7,8)^{d}\end{array}$ \\
\hline Desulfobacter & $10 \mathrm{Me} 16: 0$, cy $17: 0(\omega 7,8)^{e}$ \\
\hline $\begin{array}{l}\text { Bacteria, anaerobic } \\
\text { desaturase pathway }\end{array}$ & $18: 1 \omega 7 C^{1}$ \\
\hline \multicolumn{2}{|c|}{ 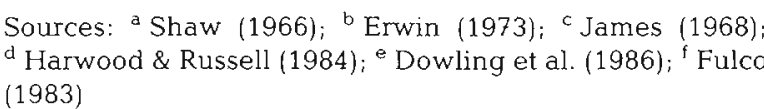 } \\
\hline
\end{tabular}


Table 4. Relative contributions of functional groups of microbes in the feeding depressions $(n=5)$ and fecal casts ( $n=$ 5) of Ptychodera bahamensis. Values represent the mean (standard deviation) percent contributed by the group to total fatty acid biomass. 'Difference between casts and depressions was significant $(p \leq 0.05)$

\begin{tabular}{|lrr|}
\hline Group & Depressions & \multicolumn{1}{c|}{ Casts } \\
\hline Eukaryotes & $8.66(1.43)$ & $8.45(1.12)$ \\
w6 series & $4.02(0.75)$ & $3.59(0.96)$ \\
w3 series & $4.65(0.76)$ & $4.86(0.57)$ \\
Photoautotrophs & $4.19(0.30)$ & $4.20(0.66)$ \\
Prokaryotes & $29.74(2.71)$ & $30.19(4.91)$ \\
Prokaryotes, less 18:1w7c & $21.24(2.33)$ & $17.85(5.10)$ \\
Desulfobacter & $2.32(0.27)$ & $2.63(1.40)$ \\
18:1w7c & $8.51(0.95)$ & $12.34(1.63)$ \\
\cline { 1 - 2 } & &
\end{tabular}

accounted for about $4 \%$. Fatty acids characteristic of the sulfate-reducing bacteria Desulfobacter spp., $10 \mathrm{Me}$ 16:0 and cy 17:0, accounted for less than $3 \%$. In all the above groups, the difference between depressions and casts was not significant (Table 4). Only for $18: 1 \omega 7 \mathrm{C}$, the biomarker for bacteria having the anaerobicdesaturase pathway, was there a significant difference, a $45 \%$ higher value in casts.

Concentrations of the functional groups' biomarkers (Fig. 4) indicated a pattern similar to that detected for individual fatty acids. Each functional group had a concentration in casts significantly lower than that in feeding depressions, except for bacteria having the anaerobic-desaturase pathway, whose biomarkers showed no difference.

Ratios of fatty acids (or of groups of fatty acids) may provide information unavailable from analyses of con-

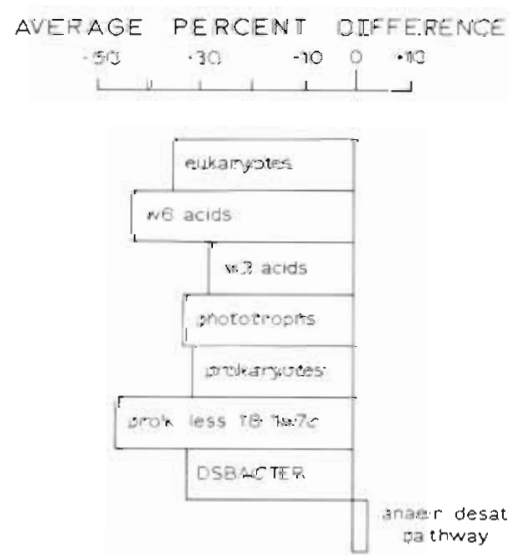

Fig. 4. Average percent difference in concentrations of functional groups of fatty acids in feeding depressions and casts of Ptychodera bahamensis. As in Fig. 3. DSBACTER: Desulfobacter spp. centrations. For example, a difference between casts and depressions in the ratio of eukaryotic to prokaryotic markers would suggest a disproportionate change in one of the groups as sediment is moved through the gut of Ptychodera. However, no such difference was observed (Table 5). In fact, the same result emerged for all combinations tested. No significant difference existed in the ratio of $\omega 6$ to $\omega 3$ markers. Ratios of trans to cis fatty acid isomers, and of cyclopropyl-fatty acids to their corresponding cis isomers, also showed no difference. Each of these latter 2 ratios has been shown to increase in prokaryotes stressed by nutrient deprivation or anoxia (Guckert et al. 1985, 1986).

\section{DISCUSSION}

There are at least 3 levels at which these results may be interpreted. The simplest approach is subtractive, i. e. to consider that differences between feeding depressions and fecal casts represent the digestive activities of Ptychodera. We emphasize that casts were sampled immediately after their appearance, so recruitment of microbes from adjacent sediment would not have affected their microbiological characteristics. A more complicated approach is to consider that while Ptychodera may digest microorganisms, it may also contribute gut flora to the microbial community that survives exposure to its alimentary canal. The most complex approach is to consider that the feeding depressions represent a greater or lesser food resource than Ptychodera actually ingests. For example, certain particles or vagile meiofauna may not be carried down the feeding funnel into the worm's burrow, or, Ptychodera may feed on subsurface deposits having a resource spectrum different from that of surface sediment. The above 3 approaches will be consulted hierarchically in discussing the results.

Table 5. Ratios of individual fatty acid isomers and functional groups in the feeding depressions $(n=5)$ and fecal casts $(n=$ 5) of Ptychodera bahamensis. Values represent the mean (standard deviation) ratio. In none of the ratios was there a significant difference between depressions and casts

\begin{tabular}{|c|c|c|}
\hline Ratio formed by: & Depressions & Casts \\
\hline Eukaryotes/Prokaryotes & $0.295\{0.064\}$ & $0.282(0.028)$ \\
\hline As above, less $18: 1017 \mathrm{C}$ & $0.416(0.103)$ & $0.492(0.089)$ \\
\hline (1) $6 /(1) 3$ & $0.865(0.098)$ & $0.750(0.239)$ \\
\hline $16: 107 t / 16: 10) 7 \mathrm{C}$ & $0.033\{0.009\}$ & $0.036(0.013)$ \\
\hline $18: 107 \mathrm{t} / 18: 107 \mathrm{C}$ & $0.056(0.020)$ & $0.044(0.013)$ \\
\hline cy $17: 0(\omega) 7,8) / 16: 1 \omega) 7 \mathrm{c}$ & $0.021(0.005)$ & $0.028(0.019)$ \\
\hline cy 19:0 $(\omega 7,8) / 18: 1 \omega 7 c$ & $0.029(0.008)$ & $0.021(0.009)$ \\
\hline
\end{tabular}




\section{Granulometry}

Evidence from granulometric analyses indicated that with respect to particle size, Ptychodera ingests sediments non-selectively at the study site. In other species of enteropneusts, non-selectivity has also been reported (Cori 1902, Knight-Jones 1953, Suchanek \& Colin 1986), although the ciliary feeding mechanisms common to the group provides them with the capability of rejecting oversized particles prior to ingestion (Barrington 1965).

\section{Meiofauna}

Meiofaunal organisms and their largest subset, nematodes, exhibited no significant differences in density between feeding depressions and fresh fecal casts. Similarly, the ratio of nematodes to total meiofauna was not significantly different. Thistle (1980) found that harpacticoid copepods were 7 times less abundant in fresh fecal mounds of subtidal Ptychodera than in adjacent surface sediment. In the present study of intertidal Ptychodera, so few harpacticoids were collected that a comparison was not possible. Duncan (1984) demonstrated that nematodes escaped from collapsing feeding depressions of Balanoglossus aurantiacus, and speculated that differences in mobility among taxa would determine the effects of the hemichordate's bioturbation on the meiobenthic community. No results consistent with Duncan's observations were found in the present study.

Given the apparent non-selective ingestion of sediment particles and accompanying meiofauna by Ptychodera, it is intriguing that the median diameter of nematodes in fecal casts was $22 \%$ larger than in feeding depressions (Fig, 2). Two hypotheses emerge. In the first, small nematodes are digested, but not to the extent that the density of nematodes significantly decreases during passage through the alimentary canal. Hylleberg (1975) found that Abarenicola pacifica, a polychaete annelid that feeds in a manner similar to Ptychodera, disproportionally digested small nematodes. Nothing is known concerning the digestive efficacy of Ptychodera, but it probably has a suite of digestive enzymes. Barrington (1940) reported amylase, lipase, and protease activity in the gut of Glossobalanus minutus, another enteropneust.

In the second hypothesis, large nematodes are ingested disproportionally to their occurrence in feeding depressions. Either Ptychodera selectively ingests large nematodes or they are more abundant in sediment beneath feeding depressions. In fecal casts of Arenicola marina, Jensen (1987) found 3 species of nematodes not found in sediments less than $8 \mathrm{~cm}$ in depth. He suggested that $A$. marina ingests subsurface meiofauna, but does not digest them. A complication with using Jensen's results as support for the second hypothesis is that the unusual nematodes he found in casts were thiobiotic (deeper-dwelling) organisms, which he (Jensen 1986, 1987) has shown are more slender than oxybiotic (surface-dwelling) species. Resolution of these 2 hypotheses awaits (at least) specific identification of the nematodes involved.

\section{Photopigments and filamentous cyanobacteria}

Passage through the gut of Ptychodera did not alter the sediment's concentration of chlorophyll a, phaeopigments, or their ratio to each other. Therefore, although diatoms and other photosynthetic organisms are abundant at the study site, the enteropneust appeared not to utilize them based on results of pigment analyses (see discussion on PLFA for a contradictory conclusion and resolution of the apparent discrepancy). The lower number of cyanobacterial filaments in casts relative to depressions may indicate selective digestion of a subset of the photosynthetic community. Alternatively, the limited motility characteristic of filamentous cyanobacteria, coupled with a positive phototropism, may be sufficient to keep most of them from being buried in the worm's feeding depression. Thus, they would tend not to be ingested and their density in fecal casts would be relatively low.

\section{Lipids}

If results of this study are approached subtractively, the conclusion is that Ptychodera digests one-third to one-half the biomass in ingested sediment. These values are typical of utilization of microbes by deposit feeders (review by Lopez \& Levinton 1987). Furthermore, the hemichordate apparently digests a wide variety of microorganisms with approximately equal facility. Findlay (1986) studied the same population of enteropneusts and reported concentrations of muramic acid, an indicator of prokaryotic biomass, to be approximately $60 \%$ lower in freshly extruded casts than in ambient sediments. Findlay's measurements of phospholipid phosphate and total PLFA also were lower in casts, but not significantly so.

In the present study, only $18: 1 \omega 7 \mathrm{C}$ apparently was unaffected by the digestive capabilities of the hemichordate. The fatty acid is characteristic of, but not unique to, eubacteria having the anaerobic-desaturase pathway, many of which are Gram-negative organisms. It is intriguing that one functional group of bacteria apparently is unaffected by Ptychodera's alimen- 
tary canal while other bacteria and eukaryotes are digested. An appealing explanation lies in the context of biofilms (Costerton et al. 1987). If bacteria having the anaerobic-desaturase pathway characteristically surround themselves with a more extensive, or more resistant, exogenous mucopolysaccharide, then they would be protected from the digestive activity of Ptychodera.

A less parsimonious level of interpreting the fatty acid data is to consider that enrichment of $18: 1 \omega 7 \mathrm{C}$ in casts results from colonization of ingested sediment by gut microbes (or at least, by microbes occurring in the gut). That is, ambient, surface-dwelling microbes containing $18: 1 \omega 7 \mathrm{c}$ may be digested to a degree comparable to other microorganisms, but gut microbes containing $18: 107 \mathrm{C}$ are added to sediment within the alimentary canal. Since the concentration of $18: 1 \omega 7 \mathrm{C}$ did not vary significantly between casts and depressions, this more-complex hypothesis requires maintenance of a balance between digestion of ambient sedimentary bacteria and addition of gut bacteria.

A final level of interpretation is to consider that the data result from Ptychodera's ingestion of subsurface sediment in addition to sediment from the feeding depression. If so, the worm utilizes a food resource in addition to that defined and measured in this study. However, since microeukaryotes and meiofauna are concentrated in the upper several $\mathrm{cm}$ of sediments (Fenchel \& Straarup 1971, Fleeger \& Decho 1987), and because the relative proportions of eukaryotic fatty acid biomarkers did not differ between casts and depressions (Table 4), we consider that surface sedi- ment constitutes the main food resource of Ptychodera. Thus, at least for the present study's samples, this third level of interpretation seems not to apply

In 2 cases, results from biochemical aspects of this study apparently were not supported by those from traditional analyses. First, counts of meiofaunal organisms did not differ in casts and depressions, yet fatty acid biomarkers of eukaryotic animals exhibited significantly lower concentrations in casts. Note that meiofaunal organisms retained on a $63 \mu \mathrm{m}$ sieve constitute only a subset of all eukaryotic, heterotrophic organisms whose membrane lipids were extracted. Thus, the apparent discrepancy between conventional and biochemical approaches illustrates the more comprehensive nature of the lipid analysis. Note also, however, that phospholipid fatty acid biomarkers specific for taxa of meiofauna are not yet known, if indeed they exist. Thus, hypotheses concerned with specific groups of meiofauna are, at present, not testable using lipid analyses.

Second, while concentrations of chlorophyll a and phaeopigments did not differ between casts and depressions, fatty acid biomarkers of eukaryotic, photosynthetic organisms had significantly lower concentrations in casts. In this study, therefore, pigment concentrations may not have reliably indicated digestion of photosynthetic microorganisms.

Acknowledgements. We thank D. Balkwill, W Burnett, P. LaRock, E. Powell, D. Thistle, D. White, and anonymous reviewers for their comments on an earlier version of this manuscript. We appreciate the openness of D. Thistle, D.

Appendix. Fatty acid profiles in the fecal cast of Ptychodera bahamensis and in the closest feeding depression. Values are in pmol fatty acid $\mathrm{g}^{-1}$ sediment (dry wt) and represent the mean ( \pm 1 standard deviation) of 5 samples

\begin{tabular}{|c|c|c|c|c|c|}
\hline Fatty acid & Feeding depression & Fecal cast & Fatty acid & Feeding depression & Fecal cast \\
\hline $\mathrm{i} 14: 0$ & $65 \pm 10$ & $25 \pm 5$ & $17: 1 \omega 8 \mathrm{c}$ & $643 \pm 94$ & $425 \pm 178$ \\
\hline $14: 0$ & $477 \pm 76$ & $296 \pm 194$ & $17: 1 \omega 6 c$ & $143 \pm 19$ & $98 \pm 36$ \\
\hline i15:0 & $443 \pm 72$ & $194 \pm 24$ & cy $17: 0$ & $55 \pm 15$ & $40 \pm 5$ \\
\hline a15:0 & $748+110$ & $413 \pm 39$ & $17: 0$ & $293 \pm 26$ & $179 \pm 48$ \\
\hline $15: 1$ & $94 \pm 12$ & $55 \pm 35$ & $18: 3 \omega 6$ & $66 \pm 12$ & $40 \pm 15$ \\
\hline $15: 0$ & $870 \pm 43$ & $466 \pm 231$ & $18: 2 \omega 6$ & $122 \pm 28$ & $72 \pm 33$ \\
\hline$i 16: 0$ & $23 \pm 4$ & $14 \pm 2$ & $18: 3 \omega 3$ & $91 \pm 34$ & $51 \pm 13$ \\
\hline $16: 1 \omega 9 c$ & $167 \pm 25$ & $114 \pm 38$ & $18: 1 \omega 9 c$ & $399 \pm 78$ & $266 \pm 48$ \\
\hline $16: 1 \omega 9 t$ & $69 \pm 7$ & $41 \pm 13$ & $18: 1 \omega 7 c$ & $1257 \pm 177$ & $1300 \pm 606$ \\
\hline $16: 107 \mathrm{C}$ & $2638 \pm 495$ & $2004 \pm 1073$ & $18: 1 \omega 7 \mathrm{t}$ & $68 \pm 13$ & $58 \pm 28$ \\
\hline $16: 107 \mathrm{t}$ & $85 \pm 11$ & $61 \pm 19$ & 18:0 & $415 \pm 56$ & $234 \pm 39$ \\
\hline $16: 105 \mathrm{c}$ & $103 \pm 33$ & $47 \pm 6$ & br19:1 & $51 \pm 10$ & $27 \pm 8$ \\
\hline $16: 1 \omega 13 \mathrm{t}$ & $134 \pm 35$ & $101 \pm 46$ & cy 19:0 & $37 \pm 14$ & $23 \pm 5$ \\
\hline $16: 0$ & $3168 \pm 879$ & $2313 \pm 970$ & $20: 4 \omega 6$ & $419 \pm 146$ & $233 \pm 32$ \\
\hline 10Me 16:0 & $287 \pm 34$ & $193 \pm 34$ & $20: 5 \omega 3$ & $606 \pm 169$ & $453 \pm 171$ \\
\hline $\mathrm{i} 17: 0$ & $222 \pm 59$ & $108 \pm 21$ & $20: 0$ & $79 \pm 30$ & $52 \pm 7$ \\
\hline $\begin{array}{l}\text { a } 17: 0 \\
\text { i17:1(1) }\end{array}$ & $\begin{array}{r}148 \pm 67 \\
81 \pm 10\end{array}$ & $\begin{array}{l}72 \pm 61 \\
49 \pm 21\end{array}$ & Unidentified & $286 \pm 54$ & $249 \pm 158$ \\
\hline $117: 107$ & $81 \pm 10$ & $49 \pm 21$ & fatty acids & & \\
\hline
\end{tabular}


White, and their coworkers in our use of their laboratories. We are grateful to those who labored in the field, including $\mathrm{K}$. Carman, P. Chin, S. Ertman, M. Foy, T Johengen, and T Scholly. P. Klein assisted greatly in the preparation of this manuscript. F.C.D. acknowledges financial support from Sigma Xi and a Florida State University Fellowship. This paper is contribution No. 1043 of the Florida State University Marine Laboratory.

\section{LITERATURE CITED}

Baird, B. H., Thistle, D. (1986). Uptake of bacterial extracellular polymer by a deposit-feeding holothurian (Isostichopus badionotus). Mar Biol. 92: 183-187

Barrington, E. J. W. (1940). Observations on feeding and digestion in Glossobalanus minutus. Quart. J. microscop. Sci. $82: 227-260$

Barrington, E. J. W. (1965). The biology of Hemichordata and Protochordata. Oliver and Boyd, London

Bligh, E. G., Dyer, W. M. (1959). A rapid method of lipid extraction and purification. Can. J. Biochem. Physiol. 35: 911-917

Boon, J. J., Liefkens, W., Rijpstra, W. I. C., Baas, M., De Leeuw, J. W. (1978). Fatty acids of Desulfovibrio desulfuricans as marker molecules in sedimentary environments. In: Krumbein, W E. (ed.) Environmental biogeochemistry and geomicrobiology, Vol. 1, The aquatic environment. Ann Arbor Science Publ., Ann Arbor, p. 355-372

Cori, C. (1902). Über das Vorkommen des Polygordius und Balanoglossus (Ptychodera) im Triester Golfe. Zool. Anz. 25: $361-365$

Costerton, J. W., Cheng, K.-J., Geesey, G. G., Ladd, T. I., Nickel, J. C. Dasgupta, M., Marrie, T. J. (1987). Bacterial biofilms in nature and disease. Ann. Rev. Microbiol 41. 435-464

DeLong, E. F., Yayanos, A. A. (1986). Biochemical function and ecological significance of novel bacterial lipids in deep-sea procaryotes. Appl. environ. Microbiol. 51. 730-737

Dinh-Nguyen, N., Ryhage, R., Stallberg-Stenhagen, S., Stenhagen, E. (1961). Mass spectrometric studies. VIII. A study of the fragmentation of normal long-chain methyl esters and hydrocarbons under electron impact with the aid of deuterium-substituted compounds. Arkiv för Kemi 18: 393-399

Dowling, N. J. E., Widdel, F., White, D. C. (1986). Phospholipid ester-linked fatty acid biomarkers of acetate-oxidizing sulphate-reducers and other sulphide-forming bacteria. J. gen. Microbiol. 132: 1815-1825

Duncan, P. B. (1984). Sediment reworking by the enteropneust Balanoglossus aurantiacus, and its effect on the meiobenthos. Dissertation, University of North Carolina at Chapel Hill

Duncan, P. B. (1987). Burrow structure and burrowing activity of the funnel-feeding enteropneust Balanoglossus aurantiacus in Bogue Sound, North Carolina, USA. P.S.Z.N.I: Mar Ecol. 8: 75-95

Erwin, J. A. (1973). Comparative biochemistry of fatty acids in eukaryotic microorganisms. In: Erwin, J. A. (ed.) Lipids and biomembranes of eukaryotic microorganisms. Acedamic, New York, p. 41-143

Fenchel, T., Straarup, B. J. (1971). Vertical distribution of photosynthetic pigment and the penetration of light in marine sediments. Oikos 22: 172-182

Findlay, R. H. (1986). Assessment of the effects of predationdisturbance on the marine sedimentary microbial community: methods and applications. Dissertation, The Florida State University, Tallahassee
Fleeger, J. W., Decho, A. W. (1987). Spatial variability of interstitial meiofauna: a review. Stygologia 3: 35-54

Fulco, A. J. (1983). Fatty acid metabolism in bacteria. Prog. Lipid Res. 22: 133-160

Gehron, M. J., White, D. C. (1983). Sensitive assay of phospholipid glycerol in environmental samples. J. microbiol. Meth. 1. 23-32

Guckert, J. B., Antworth, C. P., Nichols, P. D., White, D. C (1985). Phospholipid, ester-linked fatty acid profiles as reproducible assays for changes in prokaryotic community structure of estuarine sediments. F.E.M.S. Microbiol. Ecol. 31. $147-158$

Guckert, J. B., Hood, M. A., White, D. C. (1986). Phospholipid ester-linked fatty acid profile changes during nutrient deprivation of Vibrio cholerae: increases in the trans/cis ratio and proportions of cyclopropyl fatty acids. Appl. environ. Microbiol. 52: 794-801

Hammond, L. S. (1981). Nutrition of deposit-feeding holothuroids and echinoids (Echinodermata) from a shallow reef lagoon, Discovery Bay, Jamaica. Mar. Ecol. Prog. Ser. 10: 297-305

Harwood, J. L., Russell, N. J. (1984). Lipids in plants and microbes. Allen \& Unwin, London

Hollander, M., Wolfe, D. A. (1973). Nonparametric statistical methods. Wiley, New York

Hurlbert, S. H. (1984). Pseudoreplication and the design of ecological field experiments. Ecology 54: 187-211

Hylleberg, J. (1975). Selective feeding by Abarenicola pacifica with notes on Abarenicola vagabunda and a concept of gardening in lugworms. Ophelia 14: 113-137

Hylleberg, J., Galluci, V. F. (1975). Selectivity in feeding by the deposit-feeding bivalve Macoma nasuta. Mar. Biol. 32: $167-178$

James, A. T. (1968). The biosynthesis of unsaturated fatty acids in photosynthetic systems in lower and higher plants. In: Gran, F. C. (ed.) Cellular compartmentalization and control of fatty acid metabolism. Academic, New York, p. $25-37$

Jensen, P. (1986). Nematode fauna in the sulphide-rich brine seep and adjacent bottoms of the East Flower Garden, NW Gulf of Mexico. IV Ecological aspects. Mar. Biol. 92 489-503

Jensen, P. (1987). Differences in microhabitat, abundance, biomass and body size between oxybiotic and thiobiotic free-living marine nematodes. Oecologia (Berl.) 71 : $564-567$

Kenyon, C. N. (1972). Fatty acid composition of unicellular strains of blue-green algae. J. Bacteriol. 109: 827-834

Knight-Jones, E. W. (1953). Feeding in Saccoglossus (Enteropneusta). Proc. zool. Soc. Lond. 123: 637-654

Lopez, G. R., Levinton, J. S. (1987). Ecology of deposit-feeding animals in marine sediments. Q. Rev. Biol. 62: 235-260

Lorenzen, C. J. (1970). Determination of chlorophyll and pheopigments: spectrophotometric equations. Limnol. Oceanogr 12: 343-346

McCloskey, J. A. (1970). Mass spectrometry of fatty acid derivatives. In: Gunstone, F. D. (ed.) Topics in lipid chemistry. Wiley, New York, p. 369-440

Moriarty, D. J. W. (1982). Feeding of Holothuria atra and Stichopus chloronotus on bacteria, organic carbon and organic nitrogen in sediments of the Great Barrier Reef Aust. J. mar Freshwat. Res. 33: 255-263

Potts, M., Olie, J. J., Nickels, J. S., Parsons, J., White, D. C (1987). Variation in phospholipid ester-linked fatty acids and carotenoids of desiccated Nostoc commune (Cyanobacteria) from different geographic locations. Appl environ. Microbiol. 53: 4-9 
Rhyhage, R., Stenhagen, E. (1958). Mass spectrometric studies. I. Methyl esters of saturated normal chain carboxylic acids. Arkiv för Kemi 13: 523-534

Rijken, M. (1979). Food and food uptake in Arenicola marina. Neth. J. Sea Res. 13: 406-421

Shaw, R. (1966). The polyunsaturated fatty acids of microorganisms. Adv, Lipid Res. 4: 107-174

Sonchik, S. M., Walker, J. Q. (1985). GC applications using an auxiliary multi-purpose oven. Am. Lab. 17(2): 58-56

Stiasny, G. (1910). Zur Kenntnis der Lebenweise von Balanoglossus clavigerus Delle Chiaje. Zool. Anz. 35: 561-565

Suchanek, T H., Colin, P. L. (1986). Rates and effects of bioturbation by invertebrates and fishes at Enewetak and Bikini atolls. Bull. mar. Sci. 38; 25-34

Thistle, D. (1980). The response of a harpacticoid copepod community to a small-scale natural disturbance. J. mar. Res. 38: 381-395
White, D. C. (1986). Quantitative physicochemical characterization of bacterial habitats. In: Poindexter, J. S., Leadbetter, E. R. (eds.) Bacteria in nature, Vol. 2. Plenum, New York, p. 177-203

White, D. C., Bobbie, R. J., King, J. D., Nickels, J. S., Amoe, P. (1979a). Lipid analysis of sediments for microbial biomass and community structure. In: Litchfield, C. D., Seyfried, P. L. (eds.) Methodology for biomass determinations and microbial activities in sediments. ASTM STP 673, Am. Soc. Test. Mater., Philadelphia, p. 87-103

White, D. C., Davis, W. M., Nickels, J. S., King, J. D., Bobbie, R. J. (1979b). Determination of the sedimentary microbial biomass by extractible lipid phosphate. Oecologia (Berl.) 40: $51-62$

Yingst, J. Y. (1976). The utilization of organic matter in shallow marine sediments by an epibenthic deposit-feeding holothurian. J. exp. mar. Biol. Ecol. 23: 55-69

This article was presented by Dr S. Y Newell; it was accepted for printing on March 18, 1988 